\title{
Hemispheric Cistern
}

National Cancer Institute

\section{Source}

National Cancer Institute. Hemispheric Cistern. NCI Thesaurus. Code C32727.

The hollow space between the medial surface of the cerebral hemisphere and the falx cerebri. 